Proceedings

\title{
D-limonene and $\beta$-ocimene Attract Aphytis melinus to Increase Parasitism of California Red Scale Aonidiella aurantii (Hemip- tera: Aphididae) on Citrus ${ }^{\dagger}$
}

\author{
Khalid Mohammed 1,*, Manjree Agarwal ${ }^{2}$ and Yonglin Ren ${ }^{2}$ \\ 1 Mosul University, Iraq; khalidomairy73@uomosul.edu.iq \\ 2 Murdoch University, Australia; m.agarwal@murdoch.edu.au; y.ren@murdoch.edu.au \\ * Correspondence: khalidomairy@uomosul.edu.iq; Tel.: +9647517043443 \\ + Presented at the 1st International Electronic Conference on Entomology (IECE 2021), 1-15 July 2021; \\ Available online: https://iece.sciforum.net/.
}

Citation: Mohammed, K.; Agarwal, M.; Ren, Y. D-limonene and $\beta$-ocimene Attract Aphytis melinus to Increase Parasitism of California Red Scale Aonidiella aurantii (Hemiptera: Aphididae) on Citrus, in Proceedings of the 1st International Electronic Conference on Entomology, 1-15 July 2021, MDPI: Basel, Switzerland, doi:10.3390/IECE-10498

Published: 1 July 2021

Publisher's Note: MDPI stays neutral with regard to jurisdictional claims in published maps and institutional affiliations.

Copyright: (c) 2021 by the authors. Submitted for possible open access publication under the terms and conditions of the Creative Commons Attribution (CC BY) license (http://creativecommons.org/licenses /by/4.0/).

\begin{abstract}
Under field conditions, the natural enemies' effectiveness in controlling pests is largely correlated with their capability to spread towards infested crops. We previously reported that Aphytis melinus (Hymenoptera: Aphelinidae), a parasitoid of California red scale Aonidiella aurantii (Maskell) (Hemiptera: Diaspididae), was attracted to volatiles from citrus fruit infested with $A$. aurantii and that d-limonene and $\beta$-ocimene $A$. aurantii -induced plant volatiles were responsible for this attraction. In this study, $\mathrm{d}$-limonene and $\beta$-ocimene were examined for their attractiveness to A. aurantii parasitoid Aphytis melinus in the field after augmentative releases. Both were mixed with paraffin oil for slow release in field experiments to control the population density of $A$. aurantii by enhancing their natural enemies. The experiment was conducted in 2018 at Murdoch citrus orchard. A total of 10,000 A. melinus adults were released in different spots of the citrus orchard. The spread of the parasitoid was evaluated, for three months after the release, using yellow sticky traps activated with both of $\mathrm{d}$-limonene and $\beta$-ocimene and by monitoring the percentage parasitism of the scale on citrus fruit. Field experiments demonstrated that lures baited with isolates of d-limonene and/or $\beta$-ocimene, which significantly attracted some species of natural enemies but had no significant impact on other recruitments. The number of $A$. melinus captured during the whole trial was greater in the traps treated with volatiles than the control. Finally, we determined that overall parasitism rates were not increased by synthetic HIPV lures but found evidence that lures may increase parasitism of $A$. aurantii when there is a decrease in the amount of volatile organic compounds due to lack of healthy and infested fruit.
\end{abstract}

Keywords: d-limonene; $\beta$-ocimene; California red scale; Aphytis melinus; herbivore-induced plant volatile; conservation biological control

\section{Introduction}

California red scale, Aonidiella aurantii (Maskell) (Hemiptera: Diaspididae), is one of the most important pests of citrus worldwide [1]. Within Australia, A. aurantii is a major pest of citrus in the citrus producing regions of Queensland, Western Australia, South Australia, Victoria, and inland New South Wales [2]. Aphytis melinus is an important agent in controlling $A$. aurantii [3] utilising augmentative releases [4]. When the aim of mass release is a quick effect of natural enemies rather than their establishment, natural enemies must move from the release points and spread throughout the infested area [5]. The capacity of natural enemies to spread within infested crops is mostly the most important factor in controlling pests in the field conditions [6]. Therefore, the dispersal and hostlocation behaviour of wasps, especially released ones, are factors that clearly influence the efficiency of biological control [7, 8]. 
Herbivore-induced-plant-volatiles (HIPVs) constitute one particular group of allelochemicals, and these volatiles are composed of many organic compounds that are released when plants become infested by herbivorous insects [9.10.11.12]. HIPVs are involved in plant communication with natural enemies of the insect herbivores through the attraction of natural enemies and the repulsion of herbivores $[13,14]$. It has long been expected that manipulation of HIPVs in synthetic or natural form can be used to attract and increase populations of natural enemies within their hosts or preys population or repel pests from crop plants $[15,16]$.

To reduce reliance on pesticide use as an urgent need for sustainable agricultural methods, more studies are focusing on the ecological effect of Volatile organic compounds (VOCs) released by plants on herbivores [17, 18]. Direct evidence for the potential of synthetic plant volatiles as field attractants for beneficial insects was investigated [19, 20]. Essential oils, as a natural emission from plants, do not pose the toxicity problems of pesticides to animals and the environment [21, 22]. Plant volatiles can be considered as potential reliable green chemicals for repelling pests and attracting natural enemies of these pests. Their long-distance effects and easy production and manipulation make these molecules excellent prospects for use with crops by spraying or mixing with a slow-releasing carrier to repel insect feeding or ovipositing from host plants and guide them to non-hosts $[23,24]$.

$\mathrm{d}$-limonene and $\beta$-ocimene are monoterpenes found within a variety of plants and fruits. $\mathrm{d}$-limonene and $\beta$-ocimene are the main terpene compounds found in citrus fruit peel $[25,11,12]$. The two compounds are both found in healthy fruit but are quantitatively elevated by insect herbivory, or mechanical injury of the fruit peel $[25,11,12]$. The elevated concentrations of the above two compounds in A. aurantii infested fruit [10,11, 12] could be due to the feeding injury on the fruit rind caused by A.aurantii, which consequently attracts $A$. melinus females to their host. d-limonene is a major constituent in citrus oils (lemon, orange, mandarin, lime, and grapefruit) [26]. Despite the use of d-limonene as a repellent for many pests, especially in high concentration $[27,28]$, it is also considered as an attractant for many species of parasitoids [29, 30, 28, 11,12]. $\beta$-ocimene is considered one of the major compounds in citrus [31,32,11,12]. $\beta$-ocimene, also emitted from plants, can serve as a chemical cue for the attraction of parasitoids or predators of plant herbivores $[29,33,11,12]$. Therefore, it could be further suggested that the production of $\mathrm{d}$ limonene and $\beta$-ocimene in citrus is part of the indirect defence strategy against $A$. aurantii infestation by attracting its natural enemies.Thus, $\mathrm{d}$-limonene and $\beta$-ocimene play a key role as long range attractants of $A$. melinus females to $A$. aurantii infested citrus fruit. This study aimed to evaluate the dispersal ability of released $A$. melinus adults and their effect on the parasitism percentage, using d-limonene and $\beta$-ocimene with yellow sticky traps and scoring percentage parasitism on infested fruit. These methods have the advantage of providing both qualitative and quantitative data on the parasitoids' presence and distribution in space.

\section{Materials and Methods}

\subsection{Insect releases}

Parasitoid pupae used in the experiment, which were purchased from Biological Services Commercial Insectary (Adelaide, Australia), were maintained under laboratory conditions until adults emerged. Ten thousand parasitoid adults were released at many release points not exceeding five meters from the locations of the chemicals dispensers and equal to the number of them because low mobility of the wasps can reduce the spread, resulting in high levels of control close to the release point and decreasing effectiveness with distance, at least in the first few generations after the release [6]. This number of $A$. melinus adults is recommended by Biological Services (commercial insectary). The trial started on 6th September - in order to keep background parasitism by naturally occurring A. melinus low - when the parasitoid is scarce in the field [1] to synchronize with the 
presence of virgin adult female $A$. aurantii, which is the preferred instar of the parasitoid [4]. The adult parasitoids released were less than 48 hours old, collected by using an insect aspirator vacuum and the number quantified based on estimation. They were then segmented, and groups of around 500 adults were placed in $20 \mathrm{ml}$ vials. These were then carried to the field in a refrigerated box and attached to the mid of the trees $150-200 \mathrm{~cm}$ above the ground.

\subsection{Attractants}

Yellow sticky traps attract $A$. melinus adults [34, 3]. Besides, researchers indicate that A. melinus females are attracted to airborne cues from hosts, i.e. A. aurantii virgin females and host-infested fruit $[35,11,12]$. Lures were developed for experiments to test the attraction of d-limonene and $\beta$-ocimene to arthropods in the field (d-limonene purity is $98 \% \mathrm{EE}$ (GLC), which has been purchased from Sigma-Aldrich, and $\beta$-ocimene purity is $\geq 90 \%$, which has been purchased from Toronto Research Chemicals) because of their large increase in herbivore-induced citrus trees volatiles compared to the healthy trees, which are commercial availability and low cost. d-limonene and $\beta$-ocimene lures were tested at the dosage of $20 \mu \mathrm{l}$ [12]. Yellow steaky traps $(101 \mathrm{~mm} \times 173 \mathrm{~mm})$ that are often used to monitor insects in fields [36] were attached to orange trees and placed in the middle of the tree 150-200 cm above the ground. Every seven days, $20 \mu \mathrm{l}$ of d-limonene and $\beta$-ocimene solution formulated in paraffin oil (for slow release of the infochemcial), as well paraffin oil as the control, were deposited on a 1-cm-diameter rubber septum dispensers that were placed on the top of the yellow sticky traps. The slow dispensers were first placed in the citrus orchard on 6th September. There were 13 weekly trapping periods, the first just before the release and the others over the following 84 days. Sticky traps and lures were replaced weekly between 13 th September to 22 nd November. Once collected, the old traps were placed inside transparent plastic bags and taken to the Murdoch University laboratory, where the numbers of Aphytis spp. adults and other natural enemies were counted under a stereomicroscope, and the abundance of each species was recorded (Table 1).

Aphytis spp. were ascribed to $A$. melinus because this is by far the most abundant species suited to temperate conditions [37] and because of the great numbers that were released. Four fruits per tree were randomly collected 150-200 cm above the ground every week on the same trees on which the traps were hung on in order to assess parasitism by A. melinus both in the trees treated by d-limonene and $\beta$-ocimene dispensers and in the trees treated by paraffin oil as a control. In the laboratory, the number of live and parasitised scales in these samples were scored.

\subsection{Experimental design of a citrus orchard}

This was conducted in an unsprayed experimental citrus orchard of Murdoch University located in WA (32.30 ${ }^{\circ} \mathrm{S} 116.01^{\circ} \mathrm{E} 69 \mathrm{~m}$ AMSL), Australia, during spring and early summer (September-November) 2018. The trees in the experimental field were 25-yearold orange trees (C. sinensis (L.)), which were planted in a $5 \times 5 \mathrm{~m}$ grid. The trial was conducted in two 1-acres plots, about $500 \mathrm{~m}$ apart from each other. The trial consisted of three treatments in the citrus orchards: (1) only paraffin oil as the control; (2) $\beta$-ocimene release; and (3) d-limonene release, and the experiment was repeated twice to confirm the results. Single yellow trap sticks with the $1 \mathrm{~cm}$ diameter rubber septum were placed $20 \mathrm{~m}$ apart in a Latin square design with three replicates per treatment (12 dispensers and 12 traps total). No herbicides or insecticides were used in the entire experimental area. The temperature was obtained through the climate Data Online by the bureau of meteorology.

\subsection{Statistical analyses}

The estimated percentage of parasitism (EPP) was measured using the following formula: 


$$
\mathrm{EPP}=100 \times(\mathrm{Np} / \mathrm{Nl}+\mathrm{Np})
$$

Here, $\mathrm{Np}$ is the number of scale instars bearing A. melinus, and $\mathrm{Nl}$ is the number of live $A$. aurantii instars that are suitable hosts for this parasitoid. Population densities of the EPP, as well as the A. melinus captured, recorded in infested fruit and traps in trees treated with d-limonene and $\beta$-ocimene dispensers and trees treated with only paraffin oil dispensers as a control, were compared among the infochemical releaser tests using a one-way analysis of variance (ANOVA). Raw data that did not pass the Kolmogorov Smirnov test for normality and the Levene test for equality of variances was subjected to square-root transformation before being analysed followed by Tukey's honestly significant difference (HSD) test. Correlation analysis was used to assess the relationship between the numbers of $A$. melinus captured and EPP during the whole trial (SPSS version 24.0, Chicago, IL, USA).

\section{Results}

\subsection{The abundance of natural enemy adults}

The main natural enemies of A. aurantii found in the trials in order of abundance were Aphytis spp., Comperiella bifasciata, Rhizobius lophanthae and Mallada spp. Based on the total number of natural enemy species attracted, $\mathrm{d}$-limonene and $\beta$-ocimene attracted more than the control paraffin oil did (Table 1). Analyses conducted for three months (September, October, and November) revealed that significantly greater numbers of Aphytis spp. were trapped in the yellow sticky traps treated with d-limonene and $\beta$ ocimene dispensers than the traps treated with paraffin oil in October and November, while there was no significant difference observed in September. The number of Mallada spp. attracted to traps were significantly higher in October but not in September and November. There were no significant differences in the percentage of Comperiella bifasciata attraction towards traps despite the increase in the number of wasps oriented towards the traps treated with VOCs compared to those treated with just paraffin oil. Rhizobius lophanthae was significantly more numerous in the $\beta$-ocimene traps during September and October. Most of these species showed a trend of increasing abundance not only in the $d$ limonene and $\beta$-ocimene but also in the control area as the season progressed. A. aurantii natural enemies and their diversity are presented in Table 1.

\subsection{Aphytis melinus captures}

The total number of A. melinus captured by the yellow sticky traps positioned under rubber septums that contain d-limonene or $\beta$-ocimene was greater than the numbers captured by the traps under the rubber septums filled with only paraffin oil as a control (Figure 1). Significant differences in the weekly captures of A. melinus between d-limonene and $\beta$-ocimene on the one hand and the paraffin oil, on the other hand, were recorded in the fifth week after release $(R+35 d)$ and seventh $(R+49 d)$, eighth $(R+56 d)$, 10th $(R+70 d)$ and 12th week $(R+84)$ after the parasitoids were released. In the pre-releases, first $(R+$ $7 d)$, second $(R+14 d)$, third $(R+21 d)$, forth $(R+28 d)$, sixth $(R+42 d)$, ninth $(R+63 d)$, and the 11 th week $(R+77 d)$ after the release, only very few parasitoids were trapped, and there were no significant differences in the numbers of wasps trapped (Figure 1).

\subsection{Estimated percentage of parasitism (EPP)}

The EPP by A. melinus did not differ significantly between trees' content, VOCs dispensers and paraffin oil dispensers, before and after the release. Except 35 days after the release, parasitism percentage was significantly greater in trees containing $\beta$-ocimene dispensers than in the other trees with d-limonene or just paraffin oil dispensers (Figure 2).

\subsection{Pattern of parasitism}

The cumulative number of A. melinus captured in the sticky traps under the d-limonene $(\mathrm{P}=0.912 ; \mathrm{N}=13 ; \mathrm{P} \geq 0.000), \beta$-ocimene $(\mathrm{P}=0.902 ; \mathrm{N}=13 ; \mathrm{P} \geq 0.000)$, and paraffin oil 
dispensers $(\mathrm{P}=0.961 ; \mathrm{N}=13 ; \mathrm{P} \geq 0.000)$ were significantly correlated with EPP. The regression analysis showed that the number of wasps captured in traps under d-limonene $\left(\mathrm{R}^{2}=\right.$ $0.316 ; \mathrm{F}=5.089 ; \mathrm{P}=0.045)$ and $\beta$-ocimene $\left(\mathrm{R}^{2}=0.264 ; \mathrm{F}=3.939 ; \mathrm{P}=0.073\right)$ dispensers was also dependent on the available host density but not for the number of wasps captured in traps under paraffin oil dispensers $\left(\mathrm{R}^{2}=0.068 ; \mathrm{F}=0.808 ; \mathrm{P}=0.388\right)$. Furthermore, the EPP in trees with d-limonene $\left(\mathrm{R}^{2}=0.052 ; \mathrm{F}=0.599 ; \mathrm{P}=0.455\right), \beta$-ocimene $\left(\mathrm{R}^{2}=0.103 ; \mathrm{F}=1.267\right.$; $\mathrm{P}=0.284)$, and paraffin oil $\left(\mathrm{R}^{2}=0.129 ; \mathrm{F}=1.634 ; \mathrm{P}=0.227\right)$ was not correlated significantly to the density of vulnerable hosts. The mean minimum temperatures during the three months of the experiment (September, October and November) were (7.3, 12.5 and $\left.12.1^{\circ} \mathrm{C}\right)$, while the mean maximum temperature was $\left(20.1,23.2\right.$ and $\left.24.8^{\circ} \mathrm{C}\right)$ respectively.

\section{Discussion}

The potential of synthetic herbivore-induced plant volatiles (d-limonene and $\beta$-ocimene) in a crop dispensed via controlled-release sachets for enhancing the recruitment and residency of some beneficial insects is further supported by the field data presented here. The citrus orchard experiment demonstrated positive responses by certain insect species to d-limonene and $\beta$-ocimene-baited trees. Further, our results suggested that biological control of A. aurantii was improved by d-limonene and $\beta$-ocimene in the citrus experiment.

Previous studies have indicated that wasps often use volatile cues for host location, which makes them ideal targets for biological control programs [38, 39, 11, 12]. Some of these wasps, which were shown previously, significantly responded to d-limonene and/or $\beta$-ocimene (e.g., Aphytis melinus, Agathis bishopi and Aphidius gifuensis) [29, 33, 11, 12]. A. melinus showed a significant response to d-limonene and $\beta$-ocimene in October and November. In the current study, both synthetic HIPVs also attracted wasps in the family Encyrtidae and predators in two families (Chrysopidae and Coccinellidae). Encyrtids and Comperiella bifasciata are beneficial insects with the former being important parasitoids of A. aurantii but has not responded significantly to both synthetic HIPVs. Chrysopidae (Mallada spp.) has significantly responded to d-limonene and $\beta$-ocimene in this experiments in October, while Coccinellidae (Rhizobius lophanthae) responded significantly to just $\beta$-ocimene in September and October for the first time. Mallada spp. are an excellent general predator in the larval stage, while ladybird Rhizobius lophanthae adult and larva feed on scale insects at all stages. Both of these predators are predatory of many pests such as Aphids, Greenhouse whitefly, Scales, Mealybugs and Moth eggs and small caterpillars. The attraction of these families to $\mathrm{d}$-limonene and $\beta$-ocimene has not previously been recorded.

The success of many augmentation biological control programs depends on the dispersal ability of the natural enemy released [40,41], and on the other hand, the dispersal ability of these natural enemies towards their hosts or preys depends on many factors. These factors can affect the physiological perception and behavioural response by arthropods to volatiles under field conditions. VOCs (e.g. composition and quantity of blends, their emission, and degradation), distances at which they are bioactive, and the physiological state of arthropods that are the putative volatile receivers are all important biotic factors and can interact with abiotic factors, such as wind speed and direction, to affect arthropod response [42]. It is important to have many rather than a few or only one release point in augmentative programs [6]. Insects behaviour which drove by olfactory, among another sensory system parts, influences mate finding, food searching, avoidance of enemies, and competition [43,44]. Olfactory stimuli from infested fruit are known to be essential during host location behaviour for many parasitoids [30, 45]. In this study, A. melinus dispersed progressively from the release points to other citrus trees in the orchard over a period of 12 weeks. Our results show that releases of A. melinus during spring (September-November), when virgin female scales are most abundant relative to the other stages, reduces the percentage of scale-infested oranges in the release orchards. As abiotic conditions were variable in the field, the number of A. melinus caught in the traps 
was quite low in the first month (September) when compared with that in October and November. The compatibility in the number of parasitoids captured in the two treatments (control vs VOCs) during the first month indicates that this was mainly due to low temperature during the release of wasps as the temperature affects the duration of development of Aphytis which, in turn, influences their ability to regulate the pest's populations [46]. The results (Figure 1) revealed that the significant higher attraction of A. Melinus, which was captured on the sticky traps hanged on citrus trees with d-limonene and $\backslash$ or $\beta$ ocimene dispensers than that on trees with just paraffin oil dispensers in October and November, was likely due to the relative increase in the attractiveness of these trees owing to the presence of the synthetic HIPVs.

Regarding the incidence of parasitism, we focussed on the incidence of parasitism and found that the presence of the HIPV dispensers increased the incidence of parasitism slightly by A. melinus under the field conditions compared to parasitism percentage on the absence of HIPV dispensers (Figure 2). In particular, the similarity in the incidence of parasitism in the two treatments (control vs synthetic HIPVs) during the whole trail indicates that this was possibly due to the presence of many fruits infested with A. aurantii, both on the trees carrying synthetic HIPVs dispensers and those carrying paraffin oil dispensers, especially if we know that the amount of the d-limonene or $\beta$-ocimene in the dispensers is approximately equal to the amount of this volatiles emitted from infested fruit [12]. After 7, 21, 42 and 63 days, the numbers captured was almost zero, mainly because of the life cycle of the released parasitoids, i.e., on these dates, the parasitoid may have been in the larval stages of their life cycle. Regarding the parasitism percentage, the parasitism recorded 35 days after the release was significantly higher in trees hanging $\beta$ ocimene dispensers compared other treatments. During other weeks, the EPP was more uniform in all the release trees, with no significant differences between the treatments.

From the viewpoint of plant defence strategies, the emission of the HIPVs that attract the carnivorous natural enemies of herbivores is considered to constitute an indirect defence against herbivores [14,47]. Importantly, by combining the blend of synthetic volatiles from A. aurantii-infested trees with those released by infested citrus trees in the field, we were able to increase the incidence of parasitism of A. aurantii slightly by the parasitoid A. melinus present in the surrounding environment.

The analysis of the potential association between cumulative parasitoid captures and total EPP, and between these two parameters and the density of susceptible hosts, highlighted that d-limonene and $\beta$-ocimene influenced parasitoid dispersal (in terms of captures) towards their host. By contrast, the non-significant association on sticky traps under paraffin oil dispensers suggest that, under the infestation conditions recorded in our trial, VOCs is more important in determining parasitoid dispersal towards their host. Habitat location over longer distances may rather be accomplished by using cues, which are associated with the habitat in general than with the host itself [48], and that leads to the fact that the lack of a significant association between EPP and host density under the infestation conditions recorded in our trial, which d-limonene and $\beta$-ocimene have no influence in the increase of parasitism percentage, maybe due to the equal quantities of synthetic $d$ limonene and $\beta$-ocimene released from septum dispensers and infested fruit from one side and other side; it may be because of the parasitoids strategies that predict that oviposition preference of parasitoids should correlate with host suitability for offspring development [49]. To increase the EPP rate, we think that it needs to experiment with higher concentrations of these synthetic VOCs used in comparison with their percentage emitted from infested fruit.

d-limonene and $\beta$-ocimene are a common plant volatile, which can be found in the rind of citrus fruits, such as lemons, limes, mandarin, and oranges [32, 11,12]. However, it is also an induced volatile in citrus trees damaged by A. aurantii $[32,12]$. The attractiveness of $\mathrm{d}$-limonene and $\beta$-ocimene to A. melinus was demonstrated in olfactometer tests $[11,12]$. In the current field study, $\mathrm{d}$-limonene and $\beta$-ocimene were attractive to A. melinus. Both compounds also attracted beneficial insects in the current field study. 
Table 1. Seasonal variation (September-November) (Mean \pm SE) of CRS's natural enemies found in yellow sticky traps with controlled-release d-limonene, $\beta$-ocimene and paraffin oil dispensers in citrus orchard during 2018.

\begin{tabular}{ccccccc}
\hline Beneficial insect & Time & \multicolumn{4}{c}{ Treatments } & \\
& & d-limonene & $\beta$-ocimene & Paraffin oil & $P$ & F \\
& & & & value & \\
\hline Aphytis melinus & September & $1 \pm 0.389 \mathrm{a}$ & $1.0 \pm 0.348 \mathrm{a}$ & $0.583 \pm 0.229 \mathrm{a}$ & 0.591 & 0.534 \\
& October & $5.0833 \pm 1.062 \mathrm{a}$ & $5.667 \pm 1.281 \mathrm{a}$ & $0.917 \pm 0.229 \mathrm{~b}$ & 0.003 & 7.134 \\
& November & $6.267 \pm 1.089 \mathrm{a}$ & $6.375 \pm 1.080 \mathrm{a}$ & $1.5 \pm 0.389 \mathrm{~b}$ & 0.001 & 8.473 \\
Comperiella & September & $2.333 \pm 1.047 \mathrm{a}$ & $1.75 \pm 0.708 \mathrm{a}$ & $0.583 \pm 0.193 \mathrm{a}$ & 0.248 & 1.457 \\
bifasciata & October & $3.667 \pm 1.170 \mathrm{a}$ & $3.667 \pm 1.227 \mathrm{a}$ & $1.583 \pm 0.553 \mathrm{a}$ & 0.26 & 1.403 \\
& November & $4.933 \pm 1.244 \mathrm{a}$ & $4.6 \pm 1.249 \mathrm{a}$ & $1.933 \pm 0.511 \mathrm{a}$ & 0.102 & 2.408 \\
Mallada spp. & September & $0.4167 \pm 0.193$ & $0.583 \pm 0.229$ & $0.167 \pm 0.112$ & 0.289 & 1.29 \\
& October & $2.833 \pm 0.534 \mathrm{a}$ & $2.417 \pm 0.417 \mathrm{a}$ & $0.917 \pm 0.260 \mathrm{~b}$ & 0.007 & 5.79 \\
& November & $2.667 \pm 0.832 \mathrm{a}$ & $2.467 \pm 0.723 \mathrm{a}$ & $0.667 \pm 0.187 \mathrm{a}$ & 0.065 & 2.913 \\
Rhizobius & September & $2.5 \pm 0.584 \mathrm{ab}$ & $2.917 \pm 0.712 \mathrm{a}$ & $0.667 \pm 0.225 \mathrm{~b}$ & 0.015 & 4.785 \\
lophanthae & October & $3.167 \pm 0.878 \mathrm{ab}$ & $3.5 \pm 0.925 \mathrm{a}$ & $0.667 \pm 0.142 \mathrm{~b}$ & 0.021 & 4.37 \\
& November & $4.867 \pm 0.920 \mathrm{a}$ & $4.933 \pm 0.983 \mathrm{a}$ & $2.267 \pm 0.511 \mathrm{a}$ & 0.054 & 3.345 \\
\hline
\end{tabular}

口D-Limonene $\square$ Beta-Ocimene $\mathbf{a}$ Paraffin oil

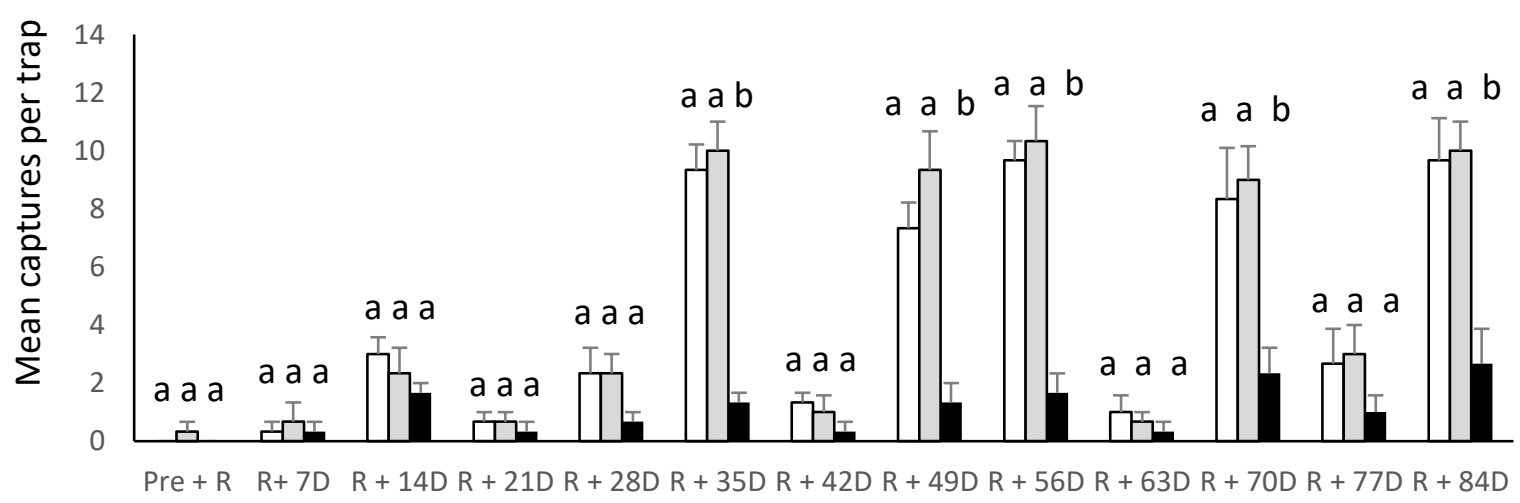

Figure 1. Mean number of adult Aphytis melinus captured $( \pm \mathrm{SE})$ in yellow sticky traps located in citrus orchards baited with controlled-release d-limonene, $\beta$-ocimene and paraffin oil dispensers during 2018 growing season in each of the thirteen weeks of the study. Different letters in the same time interval are significantly different (ANOVA $P<0.05)$. 


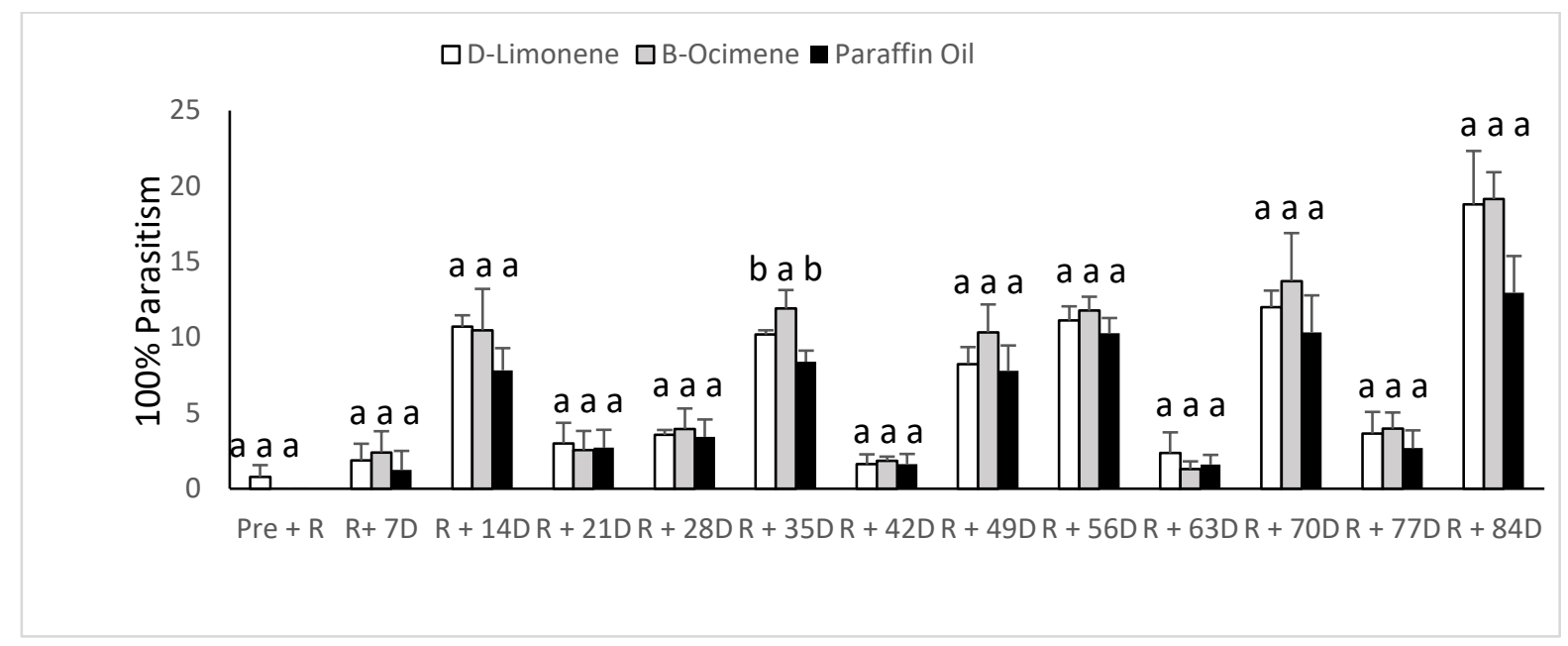

Figure 2. Parasitism $100 \%$ of adult Aphytis melinus $( \pm$ SE) in citrus orchards baited with controlled-release d-limonene, $\beta$-ocimene and paraffin oil dispensers during 2018 growing season in each of the thirteen weeks of the study. Different letters in the same time interval are significantly different (ANOVA $P<0.05$ ).

Acknowledgments: We thank University of Mosul for a scholarship and support to the first author. We thank Xin Bob Du and James Newman, Murdoch University Laboratory staff, for their technical support; Bob Fawcett, for facilitating the study orchards, releasing Aphytis melinus, and monitoring yellow sticky traps.

Conflicts of Interest: No conflicts of interest or state.

\section{References}

1. Pekas, A. Factors affecting the biological control of California red scale Aonidiella aurantii (Hemiptera: Diaspididae) by Aphytis (Hymenoptera: Aphelinidae) in eastern Spain citrus: host size, ant activity, and adult parasitoid food sources (Doctoral dissertation, Universitat Politècnica de València) 2011. DOI:10.4995/THESIS/10251/10293

2. Smith, D.; Beattie, G.A.; Broadley, R. Citrus pests and their natural enemies: integrated pest management in Australia. Australia. Queensland Department of Primary Industries. 1997.

3. Sorribas, J.; Garcia-Marí, F. Comparative efficacy of different combinations of natural enemies for the biological control of California red scale in citrus groves. Biological Control 2010, 55(1), 42-48. https://doi.org/10.1016/j.biocontrol.2010.06.012

4. Moreno, D.S.; Luck, R.F. Augmentative releases of Aphytis melinus (Hymenoptera: Aphelinidae) to suppress California red scale (Homoptera: Diaspididae) in Southern California lemon orchards. Journal of Economic Entomology 1992, 85(4), 1112-1119. https://doi.org/10.1093/jee/85.4.1112

5. Corbett, A.; Rosenheim, J.A. Quantifying movement of a minute parasitoid, Anagrus epos (Hymenoptera: Mymaridae), using fluorescent dust marking and recapture. Biological control 1996, 6(1), 35-44. https://doi.org/10.1006/bcon.1996.0005

6. Zappala, L.; Campolo, O.; Grande, S.B.; Saraceno, F.; Biondi, A.; Siscaro, G; Palmeri, V. Dispersal of Aphytis melinus (Hymenoptera: Aphelinidae) after augmentative releases in citrus orchards. European Journal of Entomology 2012, $109(4)$, p.561. DOL:10.14411/eje.2012.070

7. Suverkropp, B.P.; Bigler, F.; van Lenteren, J.C. Dispersal behaviour of Trichogramma brassicae in maize fields. Bulletin of insectology 2009, 62(1), 113-120.

8. Tabone, E.; Bardon, C.; Desneux, N. August. Study of dispersal as a selection criterion for Trichogrammatidae for biological control in cauliflower greenhouses. In XXVIII International Horticultural Congress on Science and Horticulture for People (IHC2010): International Symposium on 927, 2010, (227-235). DOI: $\underline{10.17660 / A c t a H o r t i c .2012 .927 .25}$

9. Schmelz, E.A.; Engelberth, J.; Alborn, H.T.; Tumlinson, J.H.; Teal, P.E. Phytohormone-based activity mapping of insect herbivore-produced elicitors. Proceedings of the National Academy of Sciences 2009, 106(2), 653-657. https://doi.org/10.1073/pnas.0811861106

10. Mohammed, K.; Agarwal, M.; Mewman, J.; Ren, Y. Optimization and Validation for Determination of VOCs from Lime Fruit Citrus aurantifolia (Christm.) with and without California Red Scale Aonidiella aurantii (Maskell) Infested by Using HS-SPMEGC-FID/MS. World Acad. Sci. Eng. Technol. Int. J. Biol. Biomol. Agric. Food Biotechnol. Eng. 2017, 9, 771-775.

11. Mohammed, K.; Agarwal, M.; Du, X.B.; Newman, J.; Ren, Y. Behavioural responses of the parasitoid Aphytis melinus to volatiles organic compounds (VOCs) from Aonidiella aurantii on its host fruit Tahitian lime fruit Citrus latifolia. Biological Control 2019, 133, 103-109. https://doi.org/10.1016/j.biocontrol.2019.03.015 
12. Mohammed, K.; Agarwal, M.; Li, B.; Newman, J.; Liu, T.; Ren, Y. Evaluation of d-Limonene and $\beta$-Ocimene as Attractants of Aphytis melinus (Hymenoptera: Aphelinidae), a Parasitoid of Aonidiella aurantii (Hemiptera: Diaspididae) on Citrus spp. Insects 2020, 11(1), p.44. https://doi.org/10.3390/insects11010044

13. Goggin, F.L. Plant-aphid interactions: molecular and ecological perspectives. Current opinion in plant biology 2007, 10(4), 399408. https://doi.org/10.1016/j.pbi.2007.06.004

14. Arimura, G.I.; Matsui, K.; Takabayashi, J. Chemical and molecular ecology of herbivore-induced plant volatiles: proximate factors and their ultimate functions. Plant and Cell Physiology 2009, 50(5), 911-923. https://doi.org/10.1093/pcp/pcp030

15. Kaplan, I., Attracting carnivorous arthropods with plant volatiles: the future of biocontrol or playing with fire?. Biological control 2012, 60(2), 77-89. https://doi.org/10.1016/j.biocontrol.2011.10.017

16. Uefune, M.; Choh, Y.; Abe, J.; Shiojiri, K.; Sano, K.; Takabayashi, J. Application of synthetic herbivore-induced plant volatiles causes increased parasitism of herbivores in the field. Journal of Applied Entomology 2012, 136(8), 561-567. https://doi.org/10.1111/j.1439-0418.2011.01687.x

17. Shimoda, T.; Takabayashi, J.; Ashihara, W.; Takafuji, A. Response of predatory insect Scolothrips takahashii toward herbivoreinduced plant volatiles under laboratory and field conditions. Journal of Chemical Ecology 1997, 23(8), $2033-2048$. https://doi.org/10.1023/B:JOEC.0000006487.49221.df

18. Bernasconi Ockroy, M.L.; Turlings, T.C.; Edwards, P.J.; Fritzsche-Hoballah, M.E.; Ambrosetti, L.; Bassetti, P.; Dorn, S. Response of natural populations of predators and parasitoids to artificially induced volatile emissions in maize plants (Zea mays L.). Agricultural and forest entomology 2001, 3(3), 201-209. https://doi.org/10.1046/j.1461-9555.2001.00107.x

19. Alhmedi, A.; Haubruge, E.; Francis, F. Identification of limonene as a potential kairomone of the harlequin ladybird Harmonia axyridis (Coleoptera: Coccinellidae). European Journal of Entomology 2010, 107, 541-548. DOI: 10.14411/eje.2010.062

20. Lee, J.C. Effect of methyl salicylate-based lures on beneficial and pest arthropods in strawberry. Environmental Entomology 2010, 39(2), 653-660. https://doi.org/10.1603/EN09279

21. Prinsloo, G.; Ninkovic, V.; Van der Linde, T.C.; Van Der Westhuizen, A.J.; Pettersson, J.; Glinwood, R. Test of semiochemicals and a resistant wheat variety for Russian wheat aphid management in South Africa. Journal of Applied Entomology 2007, 131(910), 637-644. https://doi.org/10.1111/j.1439-0418.2007.01213.x

22. Mohan, M.; Haider, S.Z.; Andola, H.C.; Purohit, V.K. Essential oils as green pesticides: for sustainable agriculture. Research Journal of Pharmaceutical, Biological and Chemical Sciences 2011, 2(4), 100-106.

23. Bernasconi, M.L.; Turlings, T.C.; Ambrosetti, L.; Bassetti, P.; Dorn, S. Herbivore-induced emissions of maize volatiles repel the corn leaf aphid, Rhopalosiphum maidis. Entomologia Experimentalis et Applicata 1998, 87(2), 133-142. https://doi.org/10.1046/j.15707458.1998.00315.x

24. Dudareva, N.; Negre, F.; Nagegowda, D.A.; Orlova, I. Plant volatiles: recent advances and future perspectives. Critical reviews in plant sciences 2006, 25(5), 417-440. https://doi.org/10.1080/07352680600899973

25. Chamberlain, K.; Briens, M.; Jacobs, J.H.; Clark, S.J.; Pickett, J.A. Use of honey bees (Apis mellifera L.) to detect the presence of Mediterranean fruit fly (Ceratitis capitata Wiedemann) larvae in Valencia oranges. Journal of the Science of Food and Agriculture 2012, 92(10), 2050-2054. https://doi.org/10.1002/jsfa.5742

26. Sun, J. D-Limonene: safety and clinical applications. Alternative Medicine Review 2007, 12(3), p.259.

27. Du, W.; Han, X.; Wang, Y.; Qin, Y. A primary screening and applying of plant volatiles as repellents to control whitefly Bemisia tabaci (Gennadius) on tomato. Scientific reports 2016, 6(1), 1-10. https://doi.org/10.1038/srep22140

28. Song, B.; Liang, Y.; Liu, S.; Zhang, L.; Tang, G.; Ma, T; Yao, Y. Behavioral responses of Aphis citricola (Hemiptera: Aphididae) and its natural enemy Harmonia axyridis (Coleoptera: Coccinellidae) to non-host plant volatiles. Florida Entomologist 2017, 411421. https://doi.org/10.1653/024.100.0202

29. Zimba, K.J. Using the Larval Parasitoid, Agathis Bishopi (Nixon)(Hymenoptera: Braconidae), for Early Detection of False Codling Moth, Thaumatotibia Leucotreta (Meyrick)(Lepidoptera: Tortricidae) Infested Fruit (Doctoral dissertation, Rhodes University). 2014.

30. Zimba, K.; Hill, M.P.; Moore, S.D.; Heshula, U. Agathis bishopi (Hymenoptera: Braconidae) as a potential tool for detecting oranges infested with Thaumatotibia leucotreta (Lepidoptera: Tortricidae). Journal of insect Behavior 2015, 28(5), 618-633. https://doi.org/10.1007/s10905-015-9526-0

31. Sarrou, E.; Chatzopoulou, P.; Dimassi-Theriou, K.; Therios, I. Volatile constituents and antioxidant activity of peel, flowers and leaf oils of Citrus aurantium L. growing in Greece. Molecules 2013, 18(9), 10639-10647. https://doi.org/10.3390/molecules180910639

32. Mohammed, K.; Agarwal, M.; Newman, J.; Ren, Y. Optimization of headspace solid-phase microextraction conditions for the identification of volatiles compounds from the whole fruit of lemon, lime, mandarin and orange. Journal of Biosciences and Medicines 2017, 5(3), 176-186. http://dx.doi.org/10.4236/jbm.2017.53019

33. Kang, Z.W.; Liu, F.H.; Zhang, Z.F.; Tian, H.G.; Liu, T.X. Volatile $\beta$-ocimene can regulate developmental performance of peach aphid Myzus persicae through activation of defense responses in Chinese cabbage Brassica pekinensis. Frontiers in plant science 2018, 9, p.708. https://doi.org/10.3389/fpls.2018.00708

34. Moreno, D.S.; Gregory, W.A.; Tanigoshi, L.K. Flight response of Aphytis melinus (Hymenoptera: Aphelinidae) and Scirtothrips citri (Thysanoptera: Thripidae) to trap color, size, and shape. Environmental Entomology 1984, 13(4), 935-940. https://doi.org/10.1093/ee/13.4.935 
35. Bernal, J.S.; Luck, R.F. Mate finding via a trail sex pheromone by Aphytis melinus DeBach (Hymenoptera: Aphelinidae) males. Journal of insect behavior 2007, 20(6), pp.515-525. https://doi.org/10.1007/s10905-007-9092-1

36. Laubertie, E.A.; Wratten, S.D.; Sedcole, J.R. The role of odour and visual cues in the pan-trap catching of hoverflies (Diptera: Syrphidae). Annals of Applied Biology 2006, 148(2), 173-178. https://doi.org/10.1111/j.1744-7348.2006.00046.x

37. Broughton, S. Development of an Integrated Pest Management Strategy for Citrus in Western Australia. Final Report Project No: CT0002. Western Australian Fruit Growers' Association-Citrus Council, Horticulture Australia Limited, and Department of Agriculture and Food in Western Australia Government through the Horticulture Program. 2006.

38. De Moraes, C.M.; Lewis, W.J.; Pare, P.W.; Alborn, H.T.; Tumlinson, J.H. Herbivore-infested plants selectively attract parasitoids. Nature 1998, 393(6685), 570-573. https://doi.org/10.1038/31219

39. Quilici, S.; Rousse, P. Location of host and host habitat by fruit fly parasitoids. Insects 2012, 3(4), 1220-1235. https://doi.org/10.3390/insects3041220

40. Kölliker-Ott, U.M.; Bigler, F.; Hoffmann, A.A. Field dispersal and host location of Trichogramma brassicae is influenced by wing size but not wing shape. Biological Control 2004, 31(1), 1-10. https://doi.org/10.1016/j.biocontrol.2004.04.018

41. Lavandero, B.; Wratten, S.; Hagler, J.; Jervis, M. The need for effective marking and tracking techniques for monitoring the movements of insect predators and parasitoids. Journal International Journal of Pest Management 2010, 50(3), 147-151. https://doi.org/10.1080/09670870410001731853

42. Williams III, L.; Rodriguez-Saona, C.; Castle del Conte, S.C. Methyl jasmonate induction of cotton: a field test of the 'attract and reward'strategy of conservation biological control. AoB Plants 2017, 9(5), p.plx032. https://doi.org/10.1093/aobpla/plx032

43. Lima, S.L.; Dill, L.M. Behavioral decisions made under the risk of predation: a review and prospectus. Canadian journal of zoology 1990, 68(4), pp.619-640. https://doi.org/10.1139/z90-092

44. Schoonhoven, L.M.; Van Loon, B.; van Loon, J.J.; Dicke, M. Insect-plant biology. Oxford University Press on Demand. 2005.

45. Giunti, G.; Benelli, G.; Messing, R.H.; Canale, A. Early adult learning affects host preferences in the tephritid parasitoid Psyttalia concolor (Hymenoptera: Braconidae). Journal of Pest Science 2016, 89(2), 529-537. https://doi.org/10.1007/s10340-015-0715-6

46. Rosen, D.; DeBach, P. Species of Aphytis of the world. Dr. W. Junk, The Hague, The Netherlands. 1979.

47. Allmann, S.; Baldwin, I.T. Insects betray themselves in nature to predators by rapid isomerization of green leaf volatiles. Science 2010, 329(5995), 1075-1078. DOI: 10.1126/science.1191634

48. Kost, C. Chemical communication. In Encyclopedia of ecology 2008, (557-575). Elsevier.

49. Mills, N. Parasitoids. In Encyclopedia of insects 2009 (748-751). Academic Press. 